\title{
EXCHANGE RATE AND INTEREST RATE DIFFERENTIAL IN G7 ECONOMIES*
}

\author{
Peter Golit**, Afees Salisu***, Akinwunmi Akintola*** \\ Faustina Nsonwu ${ }^{* * * *}$, Itoro Umoren******

\begin{abstract}
**Research Department, Central Bank of Nigeria, Abuja, Nigeria. Email: pdgolit@cbn.gov.nga *** Department for Management of Science and Technology Development, Ton Duc Thang University, Ho Chi Minh City, Vietnam ; Faculty of Business Administration, Ton Duc Thang University, Ho Chi Minh City, Vietnam ; Centre for Econometric \& Allied Research, University of Ibadan, Ibadan, Nigeria. Email : afees.adebare.salisu@tdtu.edu.vn

****Research Department, Central Bank of Nigeria, Abuja, Nigeria. Email: aaakintola@cbn.gov.ng

******Research Department, Central Bank of Nigeria, Abuja, Nigeria. Email: nfnsonwu@cbn.gov.ng

******Research Department, Central Bank of Nigeria, Abuja, Nigeria. Email: ieumoren@cbn.gov.ng
\end{abstract}

\begin{abstract}
We offer new insights on the dynamics of the exchange rate-interest rate differential for the case of G7 economies. We show that the nexus is better considered using an asymmetric model, as suggested by a host of previous studies. In addition, we find the role of accounting for structural breaks to be prominent. We also show differences in the nexus between euro and non-euro G7 countries, suggesting heterogeneous monetary policies. Thus, we document the strongest evidence for the sticky price hypothesis in Japan and lesser evidence in the euro countries and the United Kingdom, with Canada consistently revealing evidence for the flexible price hypothesis.
\end{abstract}

Keywords: G7 countries; asymmetry; Structural break; Exchange rate; Interest rate differential. JEL Classification: E43; F21; F31.

\author{
Article history: \\ Received : March 18, 2019 \\ Revised : October 20, 2019 \\ Accepted : October 25, 2019 \\ Available online : October 28, 2019 \\ https://doi.org/10.21098/bemp.v22i3.1147
}

\footnotetext{
The authors wish to acknowledge the useful comments by the anonymous reviewers and the managing editor - Professor Paresh Kumar Narayan. The technical support received from the econometric workshops of the Central Bank of Nigeria is graciously acknowledged.
} 


\section{INTRODUCTION}

Models of the exchange rate-interest rate differential are not new in the literature, studies exploring the diverse theoretical models (e.g., Bautista, 2006; Hacker et al., 2013; Frankel, 2014; Moosa and Burns, 2014; Andries et al., 2017; Özmen and Yilmaz, 2017) are far from conclusive, and various assumptions of an open economy continue to lead to different conclusions. Amidst these diversities, the unstable nature of the linear econometric modeling of the exchange rate and its fundamentals is brought to the fore by the burgeoning of empirical studies incorporating nonlinearities into the nexus (e.g., Christodoulakis and Mamatzakis, 2013; Ding and Yang, 2017; Bahmani-Oskooee and Motavallizadeh-Ardakani, 2018; Cheikh and Zaied, 2019). These points inform the empirical motivation for this study to explore the asymmetric nature of the exchange rate-interest rate differential in the context of the G7 countries (Canada, France, Germany, Italy, Japan, the United Kingdom, and the United States) as a case study. ${ }^{1}$

The theoretical motivation for this study is apparent from the multiple theoretical postulations. For instance, the juxtaposition of the predictions of the sticky price and flexible price hypotheses suggest potential asymmetries in the exchange rate-interest rate differential nexus (Frankel, 1979). While the sticky price, for example, predicts a short-run negative relation between the exchange rate and the interest rate differential, the flexible price, on the other hand, argues for a positive relation between them. In other words, the uncovered interest rate parity establishes a connection between the exchange rate and the interest rate differential, as long as the latter is not zero. As further presented by Auten (1963), the theory differentiates between the effects of the interest rate differential on the exchange rate when it favors the home country and when it favors the foreign country. If the positive interest rate differential favors the foreign country (i.e., the foreign interest rate exceeds the domestic interest rate), investment flows will seek a higher interest rate abroad and, hence, increase the exchange rate (i.e., a positive relation). On the other hand, because prices usually display downward rigidity, when the domestic interest rate exceeds the foreign interest rate, prices will not fall to the full extent of the contractionary monetary policy that raised the domestic interest rate in the first place. Thus, a negative relationship is expected between investment inflows and exchange rate under this scenario.

There are also technical motivations for this study that cannot be ignored. For instance, Meese and Rogoff (1983) argue that ignoring nonlinearities is one of the major reasons why macroeconomic fundamentals fail to predict exchange rates out of sample (Moosa, 2013). Ghartey (2018) also argues in support of asymmetry in the exchange rate dynamics that fits the data-generating process well and yields superior estimates, especially in the presence of structural breaks. Kilian and Taylor (2003) also argue that a nonlinear model better fits the exchange rate.

\footnotetext{
1 The analysis is conducted for four units: the euro area as a unit (comprising France, Germany, and Italy) and each of Canada, Japan, and the United Kingdom, which represent the non-euro area. The United States is implicitly featured as the reference country for which the exchange rates are described and the foreign country for which the interest rate differentials are defined. Hence, the interest rate differential is the difference between the U.S. interest rate and each of the other six country's interest rates.
} 
Similarly, Rocha (2012) demonstrates that asymmetries are present even in the dynamics of the interest rate in terms of nonlinear interactions, impacting the financial channel of monetary policy. Overall, empirically, the nonlinear relation between interest rate and exchange rate is informed by the studies of Jackman et al. (2013), Li (2011), and Ozcelebi (2019). Notably, Christodoulakis and Mamatzakis (2013) indicate that asymmetry is an important consideration in determining the exchange rates of the G7 countries, which the present study explores.

Fortified with the foregoing incentives, we proceed to adopt the nonlinear ARDL framework developed by Shin et al. (2014) to determine the asymmetric dynamics of the nexus in the presence of structural breaks. Thus, we also account for structural breaks based on the break dates revealed by Narayan and Liu's (2015) unit root test. ${ }^{2}$ This is not trivial, but necessary to account for the shifts observed from the plot of the series (see Figures 1 and 2) and their influence on the nexus. There are also theoretical considerations for why structural breaks could matter for the nexus of concern. Considering the growing integration of the world economy and the special economic cooperation between the G7 economies, the example of the global financial crisis and its aftermath could fuel concerns regarding the sensitivity of the nexus to policy shifts in the area of study. To this end, we categorize the G7 countries into euro area and non-euro area countries and hypothesize that the significance, or otherwise, of asymmetries and structural break in the nexus can vary between the two categories. We expect this unevenness between the euro and non-euro area countries, given the spillover impacts of U.S. monetary policy (the reference country) to the euro area and the bond between the euro/dollar exchange rate are empirically reported to be strong (Hanisch, 2019; Heimonen, 2009), whereas the same cannot necessarily be said of the non-euro area.

The foregoing efforts produce interesting findings that have not yet been clarified in the literature. First, we show differences in the relation between the interest rate differential and the exchange rate for the G7 countries between the euro and non-euro areas. We demonstrate that the relation is best captured in the presence of asymmetries and structural breaks for the euro countries. On the hand, only structural breaks seem to matter in the nexus for the non-euro countries, individually. We find the strongest evidence for the sticky price hypothesis in Japan and lesser evidence in the euro area and the United Kingdom while the flexible price hypothesis is observed for Canada.

The remainder of the paper is structured as follows. Section II describes the methodology. Section III explains the data and offers preliminary results. Section IV presents the main empirical results and discusses the findings. Section V concludes the paper.

\footnotetext{
2 The high frequency and trending nature of the series require us to adopt a unit root test that adequately captures the same. Among the competing tests of Narayan and Liu (2015) and Narayan and Popp (2010), preference is accorded to the former for a number of technical reasons that are described by Salisu, Adediran, Oloko, and Ohemeng (2019), Salisu and Adeleke (2016), and Salisu, Ndako, and Oloko (2019). However, because the structural break test chosen is a series-based analysis that produces a break date(s) for each series, we incorporate the breaks found for the regressand (i.e., the exchange rate) into our predictive models for both linear and nonlinear ARDL.
} 


\section{MODEL AND METHODOLOGY}

Although a number of competent and alternative models of international economics exist in the literature, the flexible price monetary model of the exchange rate proposed by Frenkel (1976) and Bilson (1978) has continued to dominate the analysis of interest rate differentials and exchange rates. ${ }^{3}$ The model is particularly rooted in three key assumptions, namely, purchasing power parity, uncovered interest parity, and the existence of stable money demand functions for domestic and foreign economies (see also Bianco et al., 2012; Civcir, 2003). The fundamentals of exchange rate determination typically consist of growth of the money supply, output, and short-term interest rate for both the domestic and foreign countries of a bilateral exchange rate. The justifications for these variables in the determination of bilateral exchange rates are well documented in the seminal paper of Frankel (1979), and we do not intend to reproduce the derivations here to avoid repetition. However, the underlying theoretical expectations are reflected in this paper, as follows: ${ }^{4}$

$$
\begin{aligned}
\Delta s_{t}= & c+\phi_{1} s_{t-1}+\beta_{1}\left(m_{t-1}-m_{t-1}^{*}\right)+\delta_{1}\left(\pi_{t-1}-\pi_{t-1}^{*}\right)+\lambda_{1}\left(i_{t-1}-i_{t-1}^{*}\right)+\gamma_{1}\left(y_{t-1}-y_{t-1}^{*}\right)+\sum_{j=1}^{p} \phi_{2 j} \Delta s_{t-j} \\
& +\sum_{i=0}^{q_{1}} \beta_{2 i} \Delta\left(m_{t-i}-m_{t-i}^{*}\right)+\sum_{i=0}^{q_{2}} \delta_{2 i} \Delta\left(\pi_{t-i}-\pi_{t-i}^{*}\right)+\sum_{i=0}^{q_{3}} \lambda_{2 i} \Delta\left(i_{t-i}-i_{t-i}^{*}\right)+\sum_{i=0}^{q_{4}} \gamma_{2 i} \Delta\left(y_{t-i}-y_{t-i}^{*}\right)+\varepsilon_{t}
\end{aligned}
$$

where $s_{t}$ is the logarithm of the exchange rate (the ratio of domestic currency to the U.S. dollar), $m_{t}$ is the logarithm of the domestic nominal money supply, $\pi_{t}$ is the inflation rate, $i_{t}$ is the interest rate, with the corresponding foreign variables (using U.S. data) denoted by an asterisk, $\mathrm{c}$ is an arbitrary constant, and $\varepsilon_{t}$ is a disturbance term. The long-run parameters for the intercept and slope coefficients are computed as $-c / \phi_{1}, \beta_{1} / \phi_{1},-\delta_{1} / \phi_{1},-\lambda_{1} / \phi_{1}$ and $-\gamma_{1} / \phi_{1}$. However, since, in the long-run, it is assumed that $\Delta s_{t-j}=0, \Delta\left(m-m^{*}\right)_{t-i}=0, \Delta\left(\pi-\pi^{*}\right)_{t-i}=0, \Delta\left(i-i^{*}\right)_{t-i}=0$, $\Delta\left(y-y^{*}\right)_{t-i}=0$, respectively, the short-run estimates are obtained as $\phi_{2 j}, \beta_{2 i}, \delta_{2 i}, \lambda_{2 i}$, and $\gamma_{2 i}$. Equation (1) can be respecified to include an error correction term, as follows:

$$
\begin{aligned}
\Delta s_{t}= & \zeta v_{t-1}+\sum_{j=1}^{p} \phi_{2 j} \Delta s_{t-j}+\sum_{i=0}^{q_{1}} \beta_{2 i} \Delta\left(m_{t-i}-m_{t-i}^{*}\right)+\sum_{i=0}^{q_{2}} \delta_{2 i} \Delta\left(\pi_{t-i}-\pi_{t-i}^{*}\right) \\
& +\sum_{i=0}^{q_{3}} \lambda_{2 i} \Delta\left(i_{t-i}-i_{t-i}^{*}\right)+\sum_{i=0}^{q_{4}} \gamma_{2 i} \Delta\left(y_{t-i}-y_{t-i}^{*}\right)+\varepsilon_{t}
\end{aligned}
$$

3 Notwithstanding variants with sticky prices by Dornbusch (1976) and with trade balances by Hooper and Morton (1982).

4 The choice of this model is underscored by the mixed order of integration evident in the unit root analyses for the relevant series 
where $v_{t-1}$ is the linear error correction term, the parameter $\zeta$ is the speed of adjustment, and the underlying long-run parameters are as previously defined.In terms of a theoretical a priori, an increase in the domestic interest rate lowers the demand for domestic currency and causes depreciation. In terms of equation (1), the coefficient of the nominal interest differential is hypothesized to be positive rather than negative. The inclusion of other variables in the specification is mainly to avoid an omitted variable bias. That said, it must be noted that the ARDL model(s) specified thus far only presumes the relation between the exchange rate and the interest rate differential to be linear (symmetric). Thus, the variant of the ARDL model that allows for our hypothesis of an asymmetric response of the exchange rate to the interest rate differential is expressed as follows:

$$
\begin{aligned}
\Delta s_{t}= & c+\phi_{1} s_{t-1}+\beta_{1}\left(m_{t-1}-m_{t-1}^{*}\right)+\delta_{1}\left(\pi_{t-1}-\pi_{t-1}^{*}\right)+\lambda_{1}^{+}\left(i_{t-1}-i_{t-1}^{*}\right)^{+} \\
& +\lambda_{1}^{-}\left(i_{t-1}-i_{t-1}^{*}\right)^{-}+\gamma_{1}\left(y_{t-1}-y_{t-1}^{*}\right)+\sum_{j=1}^{p} \phi_{2 j} \Delta s_{t-j}+\sum_{i=0}^{q_{1}} \beta_{2 i} \Delta\left(m_{t-i}-m_{t-i}^{*}\right) \\
& +\sum_{i=0}^{q_{2}} \delta_{2 i} \Delta\left(\pi_{t-i}-\pi_{t-i}^{*}\right)+\sum_{i=0}^{q_{3}} \lambda_{2 i}^{+} \Delta\left(i_{t-i}-i_{t-i}^{*}\right)^{+}+\sum_{i=0}^{q_{4}} \lambda_{2 i}^{-} \Delta\left(i_{t-i}-i_{t-i}^{*}\right)^{-} \\
& +\sum_{i=0}^{q_{5}} \gamma_{2 i} \Delta\left(y_{t-i}-y_{t-i}^{*}\right)+\varepsilon_{t}
\end{aligned}
$$

The short-run asymmetric situation can be represented as

$$
\begin{aligned}
\Delta s_{t}= & \zeta v_{t-1}+c+\sum_{j=1}^{p} \phi_{2 j} \Delta s_{t-j}+\sum_{i=0}^{q_{1}} \beta_{2 i} \Delta\left(m_{t-i}-m_{t-i}^{*}\right)+\sum_{i=0}^{q_{2}} \delta_{2 i} \Delta\left(\pi_{t-i}-\pi_{t-i}^{*}\right) \\
& +\sum_{i=0}^{q_{3}} \lambda_{2 i}^{+} \Delta\left(i_{t-i}-i_{t-i}^{*}\right)^{+}+\sum_{i=0}^{q_{4}} \lambda_{2 i}^{-} \Delta\left(i_{t-i}-i_{t-i}^{*}\right)^{-}+\sum_{i=0}^{q_{5}} \gamma_{2 i} \Delta\left(y_{t-i}-y_{t-i}^{*}\right)+\varepsilon_{t}
\end{aligned}
$$

The computation of the asymmetric effect follows the approach of Shin et al. (2014), where $\left(i_{t-1}-i_{t-1}^{*}\right)^{+}$and $\left(i_{t-1}-i_{t-1}^{*}\right)^{-}$are computed as the positive and negative partial sum decompositions of the interest differential, respectively, as follows: ${ }^{5}$

$$
\begin{aligned}
& \left(i_{t-1}-i_{t-1}^{*}\right)^{+}=\sum_{k=1}^{t} \Delta\left(i_{t-1}-i_{t-1}^{*}\right)^{+}=\sum_{k=1}^{t} \max \left(\Delta\left(i_{t-1}-i_{t-1}^{*}\right), 0\right) \\
& \left(i_{t-1}-i_{t-1}^{*}\right)^{-}=\sum_{k=1}^{t} \Delta\left(i_{t-1}-i_{t-1}^{*}\right)^{-}=\sum_{k=1}^{t} \min \left(\Delta\left(i_{t-1}-i_{t-1}^{*}\right), 0\right)
\end{aligned}
$$

Several studies have also adopted this approach to analyse the asymmetric response of exchange rates (e.g., Bahmani-Oskooee and Aftab, 2017a,b; Bahmani-Oskooee and Kanitpong, 2017; Salisu and Ndako, 2018). 
We further extend both the linear and nonlinear ARDL models to include endogenous structural breaks. For the linear (ARDL) model, the specification is as follows:

$$
\begin{aligned}
\Delta s_{t} & =c+\phi_{1} s_{t-1}+\beta_{1}\left(m_{t-1}-m_{t-1}^{*}\right)+\delta_{1}\left(\pi_{t-1}-\pi_{t-1}^{*}\right)+\lambda_{1}\left(i_{t-1}-i_{t-1}^{*}\right) \\
& +\gamma_{1}\left(y_{t-1}-y_{t-1}^{*}\right)+\sum_{j=1}^{p} \phi_{2 j} \Delta s_{t-j}+\sum_{i=0}^{q_{1}} \beta_{2 i} \Delta\left(m_{t-i}-m_{t-i}^{*}\right) \\
& +\sum_{i=0}^{q_{2}} \delta_{2 i} \Delta\left(\pi_{t-i}-\pi_{t-i}^{*}\right)+\sum_{i=0}^{q_{3}} \lambda_{2 i} \Delta\left(i_{t-i}-i_{t-i}^{*}\right) \\
& +\sum_{i=0}^{q_{4}} \gamma_{2 i} \Delta\left(y_{t-i}-y_{t-i}^{*}\right)+\sum_{r=1}^{k} D_{r} B_{r t}+\varepsilon_{t}
\end{aligned}
$$

The nonlinear ARDL (NARDL) is specified as

$$
\begin{aligned}
\Delta s_{t} & =c+\phi_{1} s_{t-1}+\beta_{1}\left(m_{t-1}-m_{t-1}^{*}\right)+\delta_{1}\left(\pi_{t-1}-\pi_{t-1}^{*}\right)+\lambda_{1}^{+}\left(i_{t-1}-i_{t-1}^{*}\right)^{+} \\
& +\lambda_{1}^{-}\left(i_{t-1}-i_{t-1}^{*}\right)^{-}+\gamma_{1}\left(y_{t-1}-y_{t-1}^{*}\right)+\sum_{j=1}^{p} \phi_{2 j} \Delta s_{t-j}+\sum_{i=0}^{q_{1}} \beta_{2 i} \Delta\left(m_{t-i}-m_{t-i}^{*}\right) \\
& +\sum_{i=0}^{q_{2}} \delta_{2 i} \Delta\left(\pi_{t-i}-\pi_{t-i}^{*}\right)+\sum_{i=0}^{q_{3}} \lambda_{2 i}^{+} \Delta\left(i_{t-i}-i_{t-i}^{*}\right)^{+}+\sum_{i=0}^{q_{4}} \lambda_{2 i}^{-} \Delta\left(i_{t-i}-i_{t-i}^{*}\right)^{-} \\
& +\sum_{i=0}^{q_{5}} \gamma_{2 i} \Delta\left(y_{t-i}-y_{t-i}^{*}\right)+\sum_{r=1}^{k} D_{r} B_{r t}+\varepsilon_{t}
\end{aligned}
$$

As shown in equations (6) and (7), the breaks are captured with the inclusion of $\sum_{r=1}^{k} D_{r} B_{r t^{\prime}}$ where $B_{r t}$ is a dummy variable for each of the breaks, defined as $B_{r t}=1$ for ${ }^{r=1} \geq T_{B_{r^{\prime}}}$ and otherwise $B_{r t}=0$. The period is represented by $t ; T_{B r}$ represents the structural break dates, where $r=1,2,3, \ldots, k$ denotes the number of breaks, and $D_{r}$ is the coefficient of the break dummy. All the other parameters are as previously defined.

\section{DATA AND PRELIMINARY ANALYSIS}

The study employs common samples (monthly data) for the period from January 2000 to December 2018, except for Japan (April 2002 to December 2018), because the data were not readily available. Data used for the study were sourced from the International Monetary Fund, International Financial Statistics, and the Federal Reserve Database. The variables include the nominal exchange rate $(E R)$ with the U.S. dollar as the reference currency and a nominal interest rate measure (INTR) as the three-month Treasury bill rate. Others are a money supply measure (MS) via an aggregate monetary index, output growth using industrial production index $(I P I)$, and the Consumer Price Index $(C P I)$ as a measure of inflation. Table 1 presents descriptive statistics of the series, namely, the mean, standard deviation, skewness, and kurtosis. 
Table 1.

\section{Summary Statistics}

This table provides basic descriptive statistics of the data. The variables ER, INTR, MS, IPI, and CPI represent Exchange Rate, Interest Rate, Money Supply, Industrial Production Index and Consumer Price Index, respectively.

\begin{tabular}{|c|c|c|c|c|c|c|c|c|c|c|}
\hline \multirow[b]{2}{*}{ Description } & $E R$ & INTR & MS & IPI & CPI & $E R$ & INTR & MS & IPI & $C P I$ \\
\hline & \multicolumn{5}{|c|}{ Euro Area } & \multicolumn{5}{|c|}{ Canada } \\
\hline Mean & 0.84 & 1.89 & 80.58 & 99.11 & 91.11 & 1.23 & 2.27 & 70.22 & 109.02 & 98.58 \\
\hline Std. Dev. & 0.13 & 1.64 & 20.66 & 4.68 & 8.75 & 0.19 & 1.52 & 27.18 & 6.79 & 9.69 \\
\hline Skewness & 0.95 & 0.51 & -0.22 & 0.25 & -0.26 & 0.41 & 0.79 & 0.38 & -0.35 & -0.10 \\
\hline \multirow[t]{2}{*}{ Kurtosis } & 3.15 & 1.88 & 1.86 & 2.74 & 1.72 & 2.06 & 2.51 & 1.95 & 3.24 & 1.87 \\
\hline & \multicolumn{5}{|c|}{ Japan } & \multicolumn{5}{|c|}{ UK } \\
\hline Mean & 105.1 & 0.28 & 91.36 & 101.34 & 101.49 & 0.63 & 2.72 & 80.46 & 103.37 & 98.38 \\
\hline Std. Dev. & 13.46 & 0.24 & 8.60 & 8.69 & 1.69 & 0.08 & 2.24 & 26.44 & 6.98 & 11.80 \\
\hline Skewness & -0.63 & 1.17 & 0.75 & 0.02 & 0.74 & 0.17 & 0.29 & -0.28 & 0.30 & 0.08 \\
\hline Kurtosis & 2.36 & 3.30 & 2.20 & 3.40 & 2.22 & 2.59 & 1.36 & 1.61 & 2.65 & 1.57 \\
\hline \multicolumn{11}{|c|}{ Reference Country (US) } \\
\hline Mean & - & 1.97 & 73.12 & 105.26 & 97.79 & & & & & \\
\hline Std. Dev. & - & 1.98 & 23.94 & 5.68 & 11.16 & & & & & \\
\hline Skewness & - & 0.97 & 0.40 & -0.17 & -0.20 & & & & & \\
\hline Kurtosis & - & 2.65 & 1.91 & 2.16 & 1.75 & & & & & \\
\hline
\end{tabular}

Starting with the mean, the Japanese yen/U.S. dollar exchange rate with a mean value of 105 reveals Japan as the economy with the weakest currency relative to the U.S. dollar, when compared to the exchange rates of the other G7 countries. The average interest rate for the period under consideration is $2 \%$ for Canada and the United Kingdom, which is the highest, and Japan is the country with the lowest interest rates. The inference from the standard deviation also is that Japan is the country with the most volatile exchange rate, while the United Kingdom has the least volatile exchange rate. However, as expected of developed economies, the standard deviation for the interest rate seems to be reasonable for both the euro and non-euro G7 countries. With respect to the distributions, we find evidence of non-zero skewness for all the series and across all the G7 countries. The kurtosis statistic is, however, mostly platykurtic in a number of countries, except in a few instances in the case of Japan, Canada, and the euro area. These differences could support our assumption of different responses of exchange rates to changes in the interest rate differential across countries.

Figures 1 and 2 are graphical illustrations of comovements between the exchange rate and the interest rate, as well as between the exchange rate and the interest rate differential, respectively. A cursory look at Figure 1 shows that comovements between the exchange rate and interest have mainly been in the opposite direction, with the likely exception of the euro area. That is, unlike the non-euro G7 countries, there are few instances, particularly in the early period of the sample, where the exchange rate and interest rate appear to be moving in the same direction in the euro area. Similarly, the plots of the exchange rate and the interest rate differential in Figure 2 mostly move equally in the opposite direction, but the movement is mixed in the case of the euro area. 
Figure 1.

Exchange Rate and Interest Rate Movements in G7 Countries

The first to fourth quadrant represent figures for Euro area, Canada, Japan, and UK respectively.

Exchange Rate and Interest Rate in Euro Area, 2000M1 to 2018M12

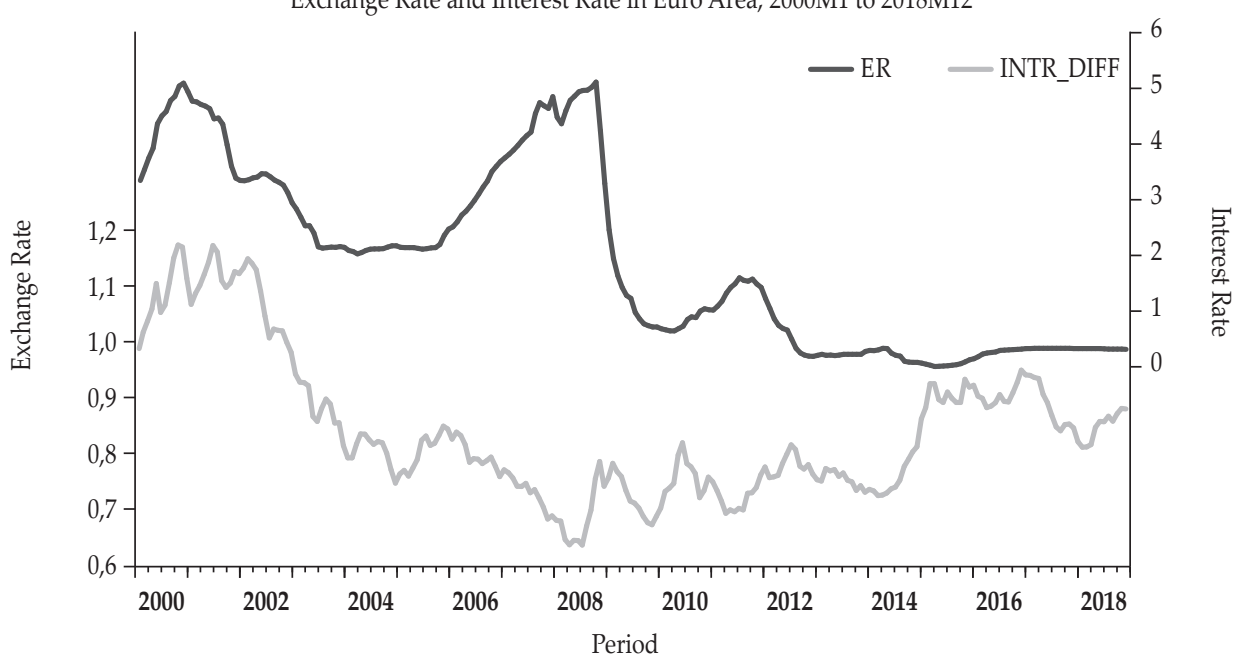

Exchange Rate and Interest Rate in Canada, 2000M1 to 2018M12

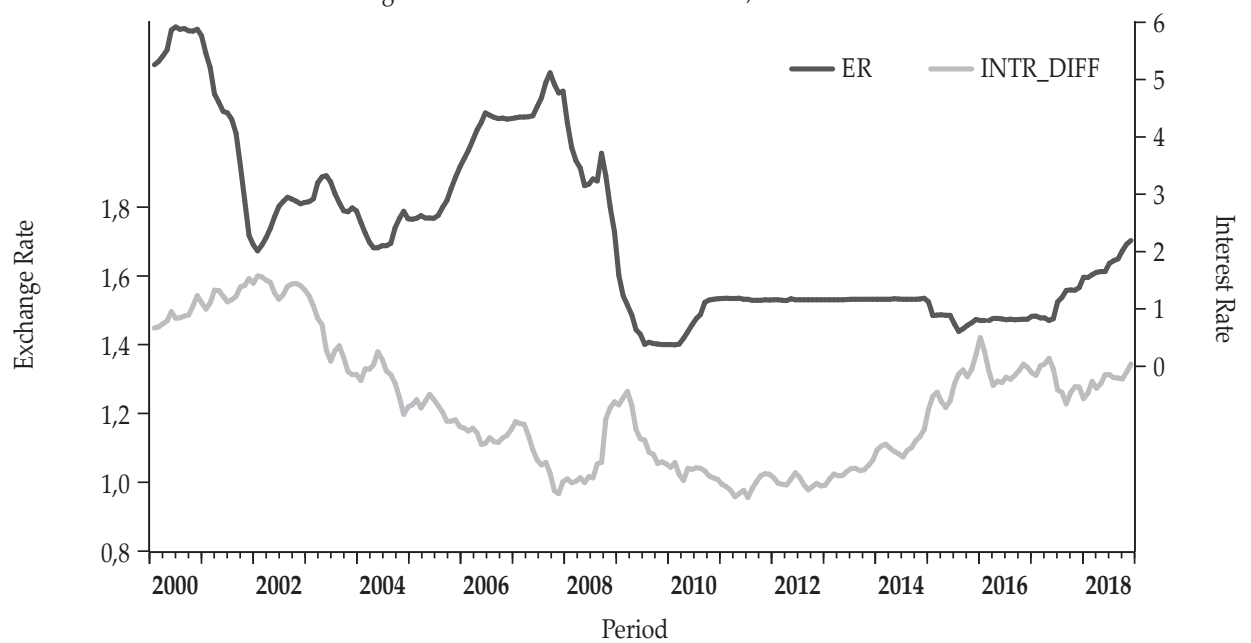


Figure 1.

Exchange Rate and Interest Rate Movements in G7 Countries (Continued)

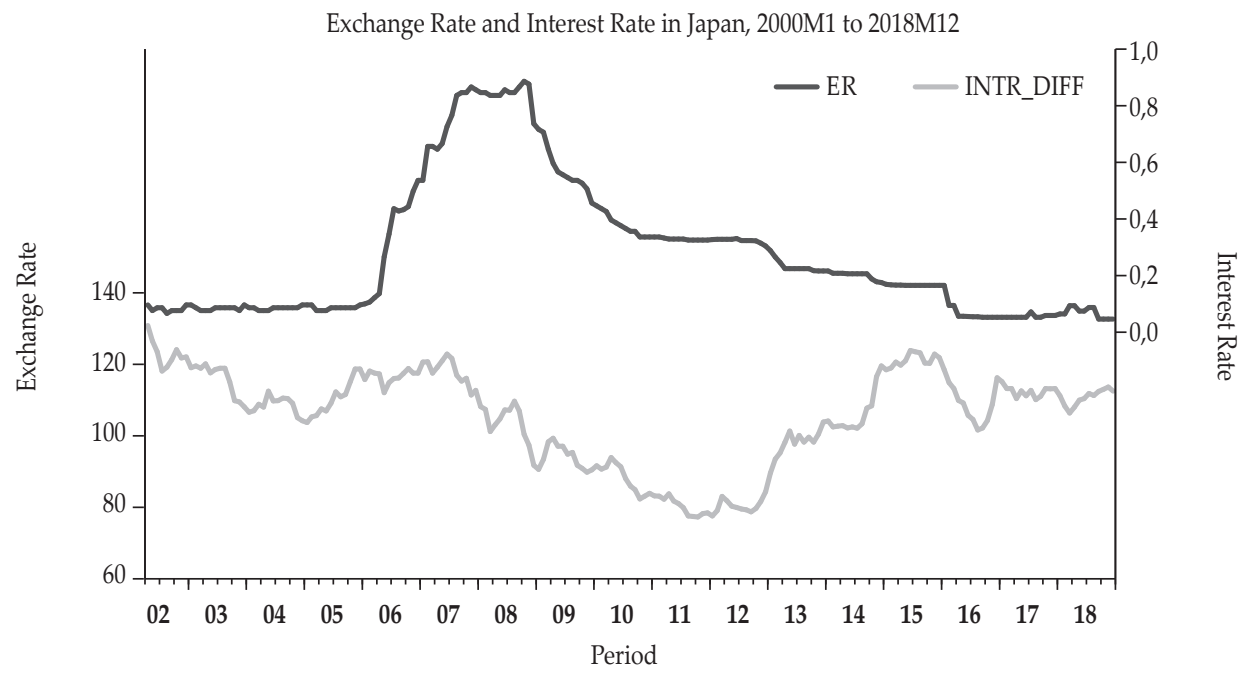

Exchange Rate and Interest Rate in UK, 2000M1 to 2018M12

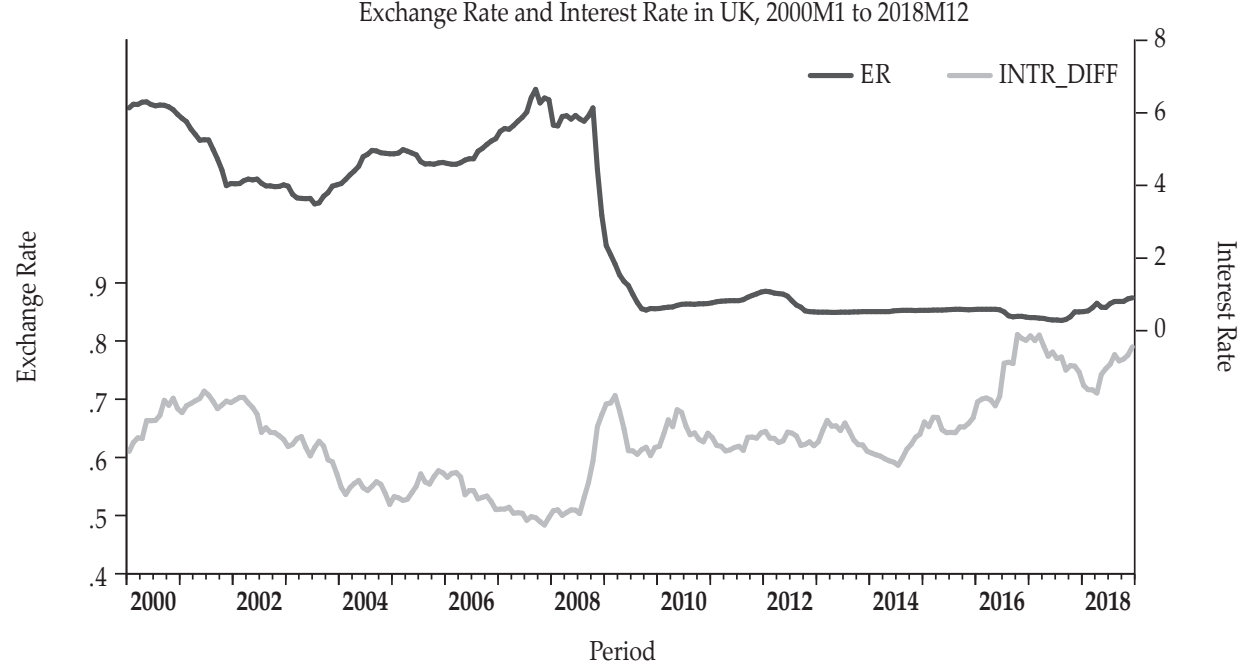


Figure 2.

Exchange Rate and Interest Rate Differentials in G7 Countries

The first to fourth quadrant represent figures for Euro area, Canada, Japan, and UK respectively.

Exchange Rate and Interest Rate Differential in Euro Area, 2000M1 to 2018M12

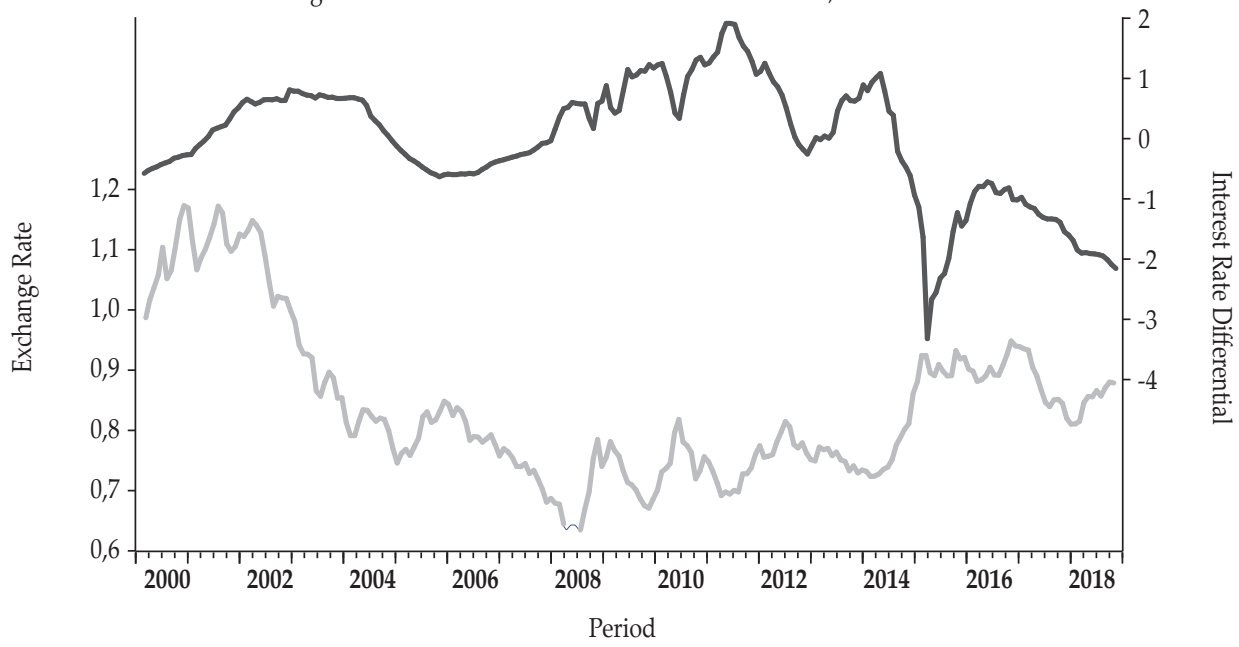

Exchange Rate and Interest Rate Differential in Canada, 2000M1 to 2018M12

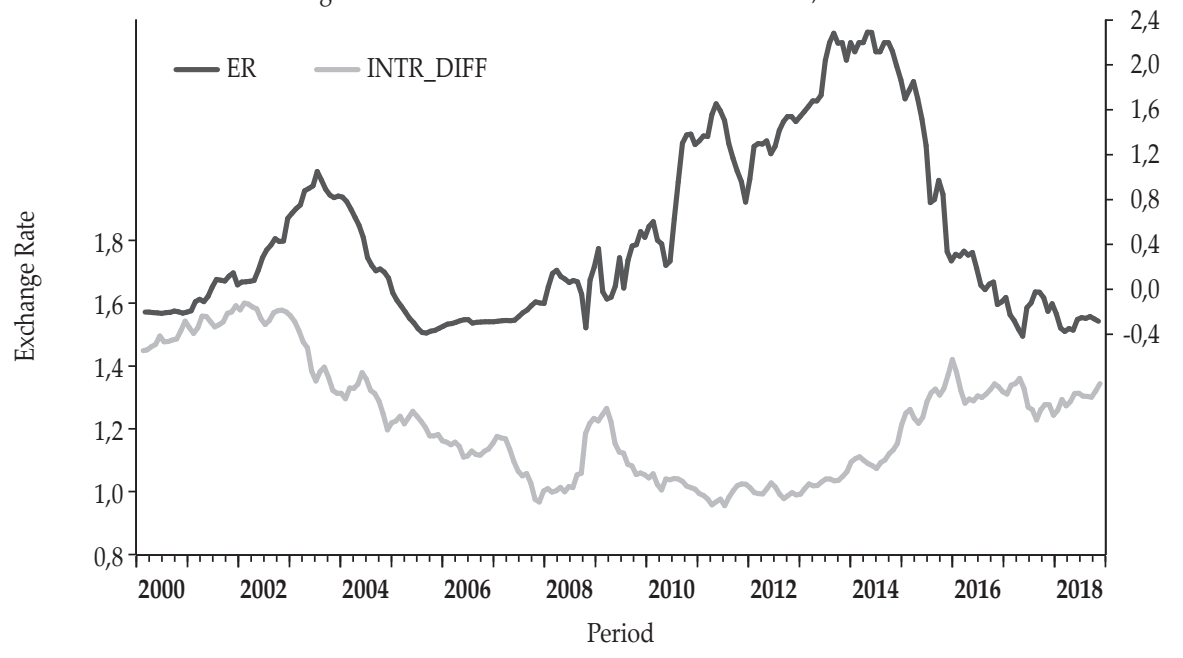

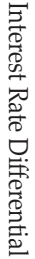


Figure 2.

Exchange Rate and Interest Rate Differentials in G7 Countries (Continued)
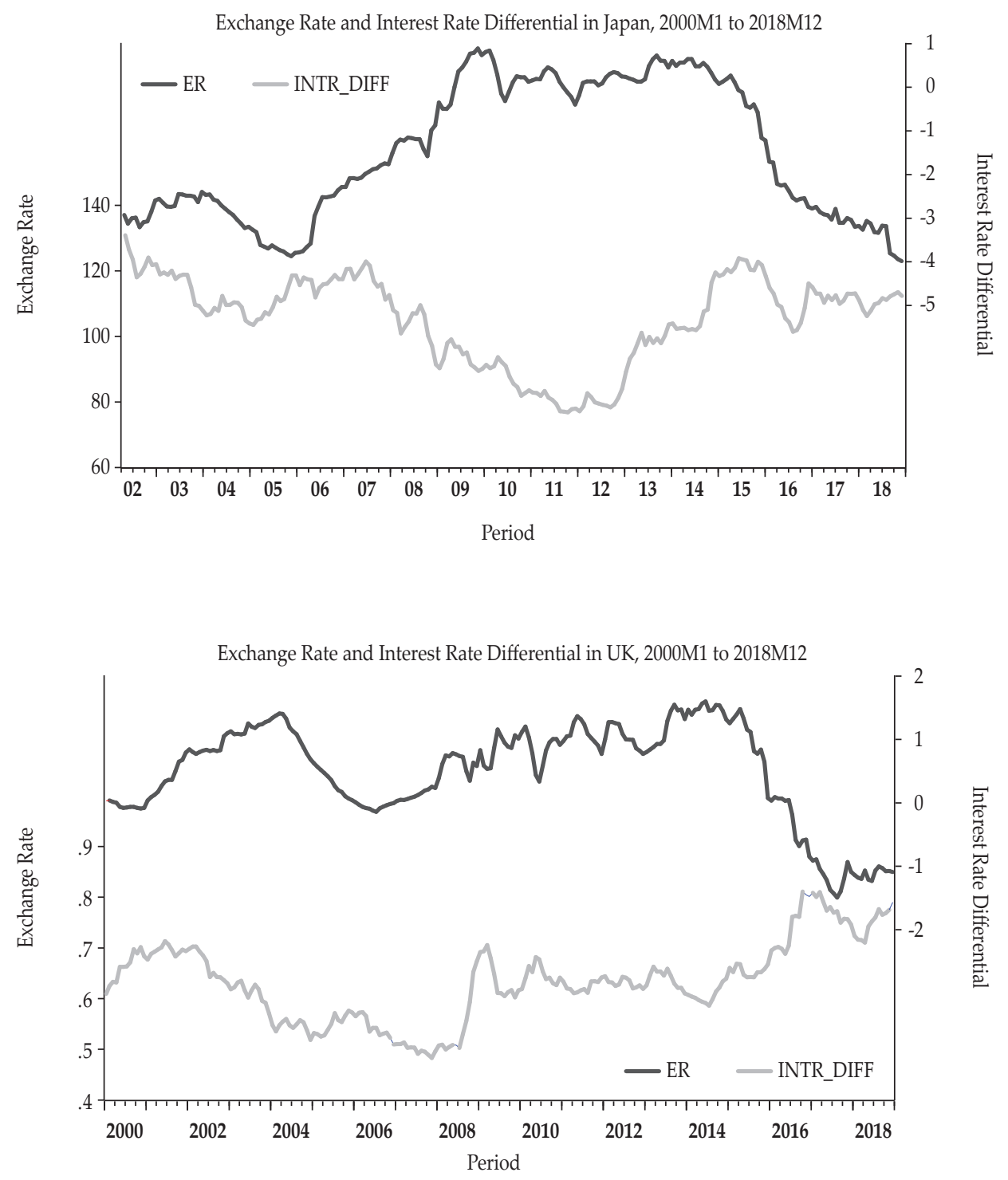
To test the stationarity of the series, we explore both the conventional augmented Dickey-Fuller (ADF) test, as well as the version that accounts for structural breaks. The unit root test results are documented in Table 2, where the order of integration tends to hover around I(0) and I(1). The fact that this evidence of mixed order of integration reported in the table holds for ADF tests both with and without structural breaks thus reaffirms our choice of estimation technique, namely, the linear and nonlinear ARDL models. The ARDL framework allows for the combination of the series with a mixed order of cointegration. For more reliability, we apply the Narayan-Liu (2015) unit root test (for motivation, see Salisu and Adeleke, 2016; Salisu, Adediran, Oloko, and Ohemeng, 2019; Salisu, Ndako and Oloko, 2019) to confirm the order of integration of the series and to obtain break dates for the regressand to be carried forward to estimate the model.

Table 2.

Unit Root Test Results

This table presents results of unit root tests. Three tests are used: namely, ADF, ADF with a break and the Narayan and Liu break tests. Here, a, b and c represent, $1 \%, 5 \%$ and $10 \%$ levels of significance, respectively. The superscripts ${ }^{\wedge}$ and \# represent unit root test equations with 'constant only' and 'constant and trend', respectively. The accompanying values in round brackets are the optimal lags. I(d) represent the order of integration indicated by the test.

\begin{tabular}{|c|c|c|c|c|c|c|c|c|c|}
\hline \multirow{2}{*}{ Country } & \multicolumn{3}{|c|}{ ADF Unit Root Test } & \multicolumn{3}{|c|}{ ADF Test with Structural Break } & \multicolumn{3}{|c|}{ Narayan and Liu (2015) Unit Root Test } \\
\hline & Series & Statistics & $\mathrm{I}(\mathrm{d})$ & Statistics & $\mathrm{I}(\mathrm{d})$ & Break Date & Statistics & $\mathrm{I}(\mathrm{d})$ & Break Date \\
\hline \multirow[t]{5}{*}{ Euro Area } & CPI & $-3.367(13)^{b f}$ & $\mathrm{I}(1)$ & $-14.358(0)^{a \sharp}$ & $\mathrm{I}(1)$ & 2009 M10 & $-14.109^{a^{a}}$ & $\mathrm{I}(1)$ & 2014M07 \\
\hline & IPI & $-5.554(2)^{a^{\wedge}}$ & $\mathrm{I}(1)$ & $-6.185(3)^{a^{n}}$ & $\mathrm{I}(0)$ & 2008 M09 & $-3.421^{\text {a* }}$ & $\mathrm{I}(0)$ & 2008M05 \\
\hline & INTR & $-10.995(0)^{a^{\wedge}}$ & $\mathrm{I}(1)$ & $-5.860(3)^{\mathrm{a}^{\wedge}}$ & $\mathrm{I}(0)$ & 2015 M04 & $-8.984^{a^{\sharp}}$ & $\mathrm{I}(0)$ & 2008M11, 2012M01 \\
\hline & MS & $-10.283(9)^{a^{x}}$ & $\mathrm{I}(2)$ & $-6.256(0)^{\mathrm{a}^{\mathrm{A}}}$ & $\mathrm{I}(0)$ & 2000 M11 & $-7.465^{a \sharp}$ & $\mathrm{I}(1)$ & 2009M01, 2014M11 \\
\hline & $E R$ & $-11.064(0)^{\text {a }}$ & $\mathrm{I}(1)$ & $-11.562(0)^{a \sharp}$ & $\mathrm{I}(1)$ & $2008 \mathrm{M} 10$ & $-10.342^{a a^{f}}$ & $\mathrm{I}(1)$ & 2002M12 \\
\hline \multirow[t]{5}{*}{ Canada } & CPI & $-3.676(1)^{b \neq}$ & $\mathrm{I}(0)$ & $-5.026(1)^{b f}$ & $\mathrm{I}(0)$ & 2002M01 & $-5.667^{\mathrm{a}^{\sharp}}$ & $\mathrm{I}(0)$ & - \\
\hline & IPI & $-3.844(14)^{b f}$ & $\mathrm{I}(1)$ & $-5.622(0)^{\mathrm{a}}$ & $\mathrm{I}(0)$ & 2000M11 & $-7.907^{\sharp}$ & $\mathrm{I}(0)$ & 2007M12 \\
\hline & INTR & $-5.571(1)^{\mathrm{a}^{\ddagger}}$ & $\mathrm{I}(1)$ & $-5.386(2)^{\mathrm{a}^{\sharp}}$ & $\mathrm{I}(0)$ & 2008M09 & $-31.708^{a f}$ & $\mathrm{I}(0)$ & 2008M01 \\
\hline & MS & $-12.987(0)^{2^{2}}$ & $\mathrm{I}(1)$ & $-13.747(0)^{a^{n}}$ & $\mathrm{I}(1)$ & 2008M06 & $-15.106^{a f}$ & $\mathrm{I}(1)$ & 2003M09, 2008M12 \\
\hline & $E R$ & $-10.817(0)^{a \ddagger}$ & $\mathrm{I}(1)$ & $-11.852(0)^{\text {a\# }}$ & $\mathrm{I}(1)$ & 2008M10 & $-9.294^{a^{\sharp}}$ & $\mathrm{I}(1)$ & 2014M12 \\
\hline \multirow[t]{5}{*}{ Japan } & CPI & $-11.364(0)^{a f}$ & $\mathrm{I}(0)$ & $-13.186(0)^{a \sharp}$ & $\mathrm{I}(1)$ & 2014M04 & $-11.384^{a f}$ & $\mathrm{I}(1)$ & 2008M11, 2014M04 \\
\hline & IPI & $-3.117(12)^{b^{\wedge}}$ & $\mathrm{I}(0)$ & $-7.343(0)^{\mathrm{a}^{\mathrm{n}}}$ & $\mathrm{I}(0)$ & 2003M08 & $-16.271^{a f}$ & $\mathrm{I}(0)$ & 2008M11, 2012M08 \\
\hline & INTR & $-13.280(0)^{a z}$ & $\mathrm{I}(1)$ & $-5.640(0)^{\mathrm{a} a}$ & $\mathrm{I}(0)$ & $2006 \mathrm{M} 02$ & $-69.975^{a f}$ & $\mathrm{I}(1)$ & 2007M09, 2016M02 \\
\hline & MS & $-10.520(0)^{a t}$ & $\mathrm{I}(1)$ & $-11.945(0)^{\mathrm{a}^{a}}$ & $\mathrm{I}(1)$ & 2008M10 & $-9.732^{2^{\sharp}}$ & $\mathrm{I}(1)$ & 2005M12 \\
\hline & $E R$ & $-11.088(0)^{a^{\sharp}}$ & $\mathrm{I}(1)$ & $-11.490(0)^{\text {a\# }}$ & $\mathrm{I}(1)$ & 2016M12 & $-9.283^{a^{\sharp}}$ & $\mathrm{I}(1)$ & 2012M11 \\
\hline
\end{tabular}


Table 2.

Unit Root Test Results (Continued)

\begin{tabular}{|c|c|c|c|c|c|c|c|c|c|}
\hline \multirow{2}{*}{ Country } & \multicolumn{3}{|c|}{ ADF Unit Root Test } & \multicolumn{3}{|c|}{ ADF Test with Structural Break } & \multicolumn{3}{|c|}{ Narayan and Liu (2015) Unit Root Test } \\
\hline & Series & Statistics & $\mathrm{I}(\mathrm{d})$ & Statistics & $\mathrm{I}(\mathrm{d})$ & Break Date & Statistics & $\mathrm{I}(\mathrm{d})$ & Break Date \\
\hline \multirow[t]{5}{*}{ UK } & CPI & $-14.031(10)^{\mathrm{a}^{\wedge}}$ & $\mathrm{I}(2)$ & $-16.208(0)^{a^{\wedge}}$ & $\mathrm{I}(1)$ & 2001M01 & $-18.06 \mathrm{a}^{\mathrm{a}}$ & $\mathrm{I}(1)$ & - \\
\hline & IPI & $-2.950(13)^{b^{\wedge}}$ & $\mathrm{I}(1)$ & $-11.585(0)^{a^{\wedge}}$ & $\mathrm{I}(0)$ & 2000M11 & $-18.278^{a^{a}}$ & $\mathrm{I}(0)$ & 2008M11 \\
\hline & INTR & $-5.148(2)^{a \sharp}$ & $\mathrm{I}(1)$ & $-7.174(3)^{a t}$ & $\mathrm{I}(0)$ & 2008M10 & $-15.136^{a^{a}}$ & $\mathrm{I}(1)$ & 2003M08, 2008M11 \\
\hline & MS & $-4.767(4)^{\mathrm{a} \#}$ & $\mathrm{I}(1)$ & $-8.914(3)^{a a^{f}}$ & $\mathrm{I}(1)$ & 2010M02 & $-8.9254^{a f}$ & $\mathrm{I}(1)$ & 2010M04, 2016M01 \\
\hline & $E R$ & $-11.494(0)^{\mathrm{a} a}$ & $\mathrm{I}(1)$ & $-12.362(0)^{a \sharp}$ & $\mathrm{I}(1)$ & 2008 M11 & $-11.112^{a \sharp}$ & $\mathrm{I}(1)$ & \\
\hline \multirow[t]{4}{*}{ US } & CPI & $-9.852(1)^{\mathrm{a}^{\sharp}}$ & $\mathrm{I}(1)$ & $-10.998(1)^{\text {ał }}$ & $\mathrm{I}(1)$ & 2008 M11 & $-7.565^{\mathrm{a}}$ & $\mathrm{I}(1)$ & 2008M08, 2014M10 \\
\hline & IPI & $-5.554(2)^{\mathrm{a}^{\mathrm{x}}}$ & $\mathrm{I}(1)$ & $-6.185(3)^{a^{\wedge}}$ & $\mathrm{I}(0)$ & 2008 M09 & $-7.397^{a \sharp}$ & $\mathrm{I}(0)$ & 2008M09, 2015M09 \\
\hline & INTR & $-9.514(0)^{\mathrm{a} \#}$ & $\mathrm{I}(1)$ & $-10.283(0)^{a \#}$ & $\mathrm{I}(1)$ & 2009 M01 & $-15.260^{a *}$ & $\mathrm{I}(1)$ & 2006M05, 2008M11 \\
\hline & MS & $-12.145(0)^{\mathrm{a} a \mathrm{f}}$ & $\mathrm{I}(1)$ & $-13.323(0)^{a *}$ & $\mathrm{I}(1)$ & 2011 M08 & $-11.602^{a^{\sharp}}$ & $\mathrm{I}(1)$ & 2008M09 2011M04 \\
\hline
\end{tabular}

\section{RESULTS AND DISCUSSION}

\section{A. Main Results}

The theoretical perspective informing the a priori expectation of the exchange rate and interest rate differential relation, states that an increase in the interest rate differential favoring the domestic economy will lead to more foreign currency chasing the domestic currency, thereby leading to foreign capital inflows that will ultimately lead to appreciation of the domestic currency. This effect indicates a negative relation between the exchange rate and the interest rate differential. However, an increase in the domestic interest rate, holding the foreign rate (the U.S. interest rate) constant, will not necessarily lead to more foreign capital inflows into the domestic economy. Due to the level of economic instability, it will lead to depreciation of the domestic currency, thereby indicating a positive relation with interest rate differential. In an attempt to draw a meaningful inference on the extent to which these assertions define the movement of the exchange rate along with the interest rate differential in the G7 countries, we consider both the linear and nonlinear ARDL models, accounting for structural breaks in the data. The estimated results are reported in Tables 3 to 6.

The results using the euro as a unit are shown in Table 3, and those for Canada, Japan, and the United Kingdom (the non-euro area) are shown in Tables 4 to 6, respectively. Four variants of the ARDL model are presented in the tables: the linear ARDL models with and without structural breaks in the data and their nonlinear counterparts (i.e., nonlinear ARDL models without and with structural breaks). However, not all the models perform equally well across the samples in terms of diagnostics, model performance criteria, and the existence of cointegration (longrun relation). In all countries, the effect of structural breaks on the results is highly influential. This is evident in the bounds cointegration test results, which improved 
after we accounted for structural breaks on either the linear or asymmetric ARDL model Although not as pronounced as the effect of structural breaks on cointegration, the results also raise a strong case for accounting for asymmetry. We report differing impacts of positive and negative interest rate differentials on the exchange rates across the four samples, supporting previous studies (e.g., Li, 2011; Jackman et al., 2013; Ozcelebi, 2019).

Based on the objective of the study, which is focused on the relation between the interest rate differential and the exchange rate, we dwell more on the results that produce better estimates of cointegration between the variables and better diagnostics. In line with one of the focuses of the study, which is to compare the results for the euro and non-euro G7 countries, we highlight that the best model for the former is the nonlinear ARDL with structural breaks, while the latter, the linear ARDL with structural breaks, gives better estimates. This is not an absolute, however, since some evidence of asymmetry reported for the non-euro area cannot be ignored. We find a negative relation between the variables prominent in the euro area, whether linear or nonlinear. Even when positive and negative asymmetries give rise to positive and negative effects, respectively, it is the negative effect that is found to be statistically significant. Conversely, in the non-euro area, a positive effect is more pronounced in Canada in both the short and long-run, even when positive and negative asymmetries also lead to positive and negative changes on the exchange rate, respectively. Japan also records different results from the euro area, in that positive and negative asymmetries produce negative and positive impacts on the exchange rate, respectively. However, Japan and the United Kingdom record predominantly negative impacts, as for the euro area.

The sticky price hypothesis that specifies a negative relation, especially in the short run, between the interest rate differential and the exchange rate appears to be supported by evidence in Japan; however, the situation is less clear in the euro area and in the United Kingdom, where the negative relation between the exchange rate and the interest rate differential extends to the long-run. On the other hand, evidence obtained for Canada appears to validate the flexible price hypothesis, with a positive nexus between the exchange rate and the interest rate differential in the short and long-run. 


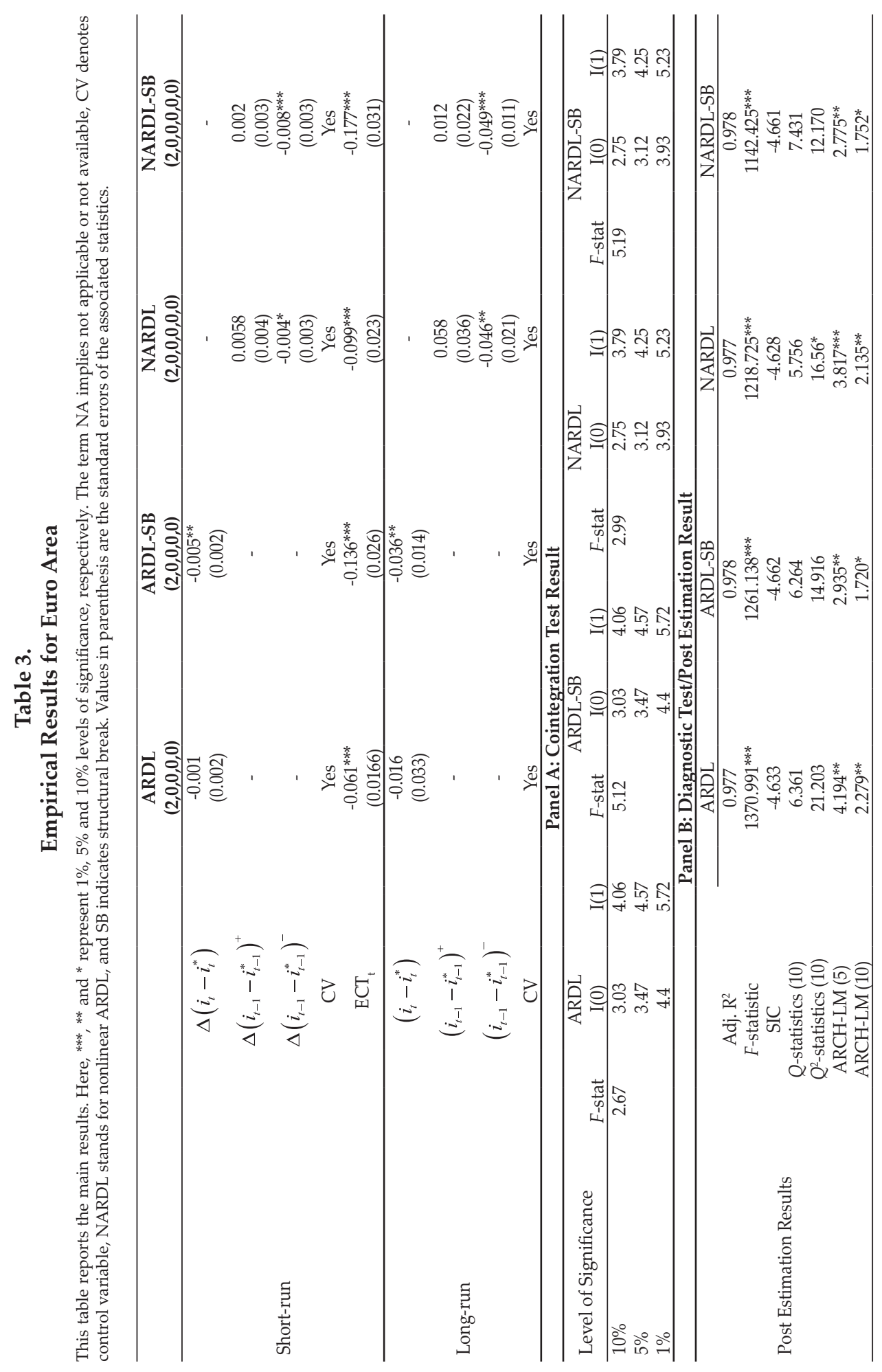




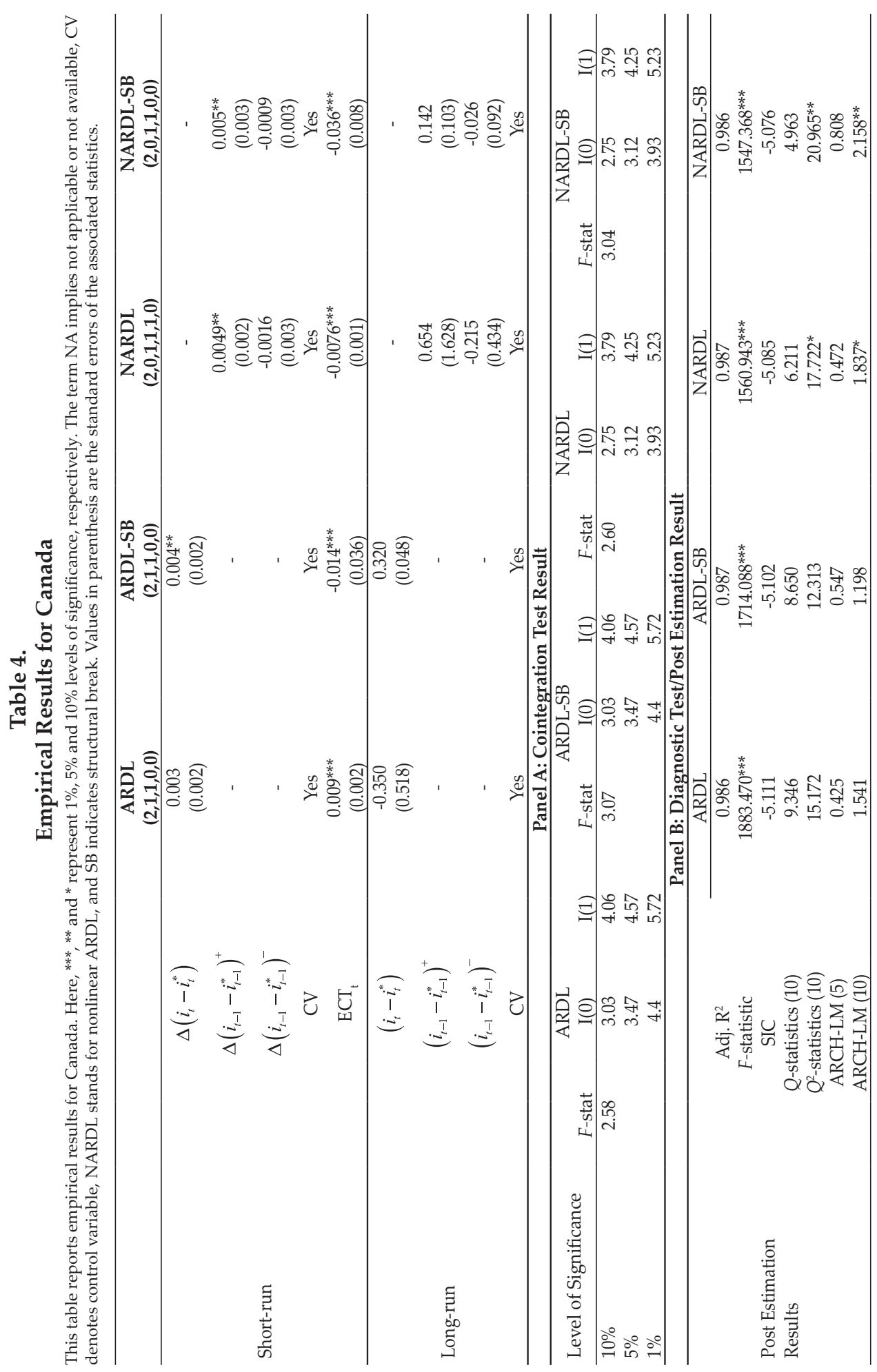




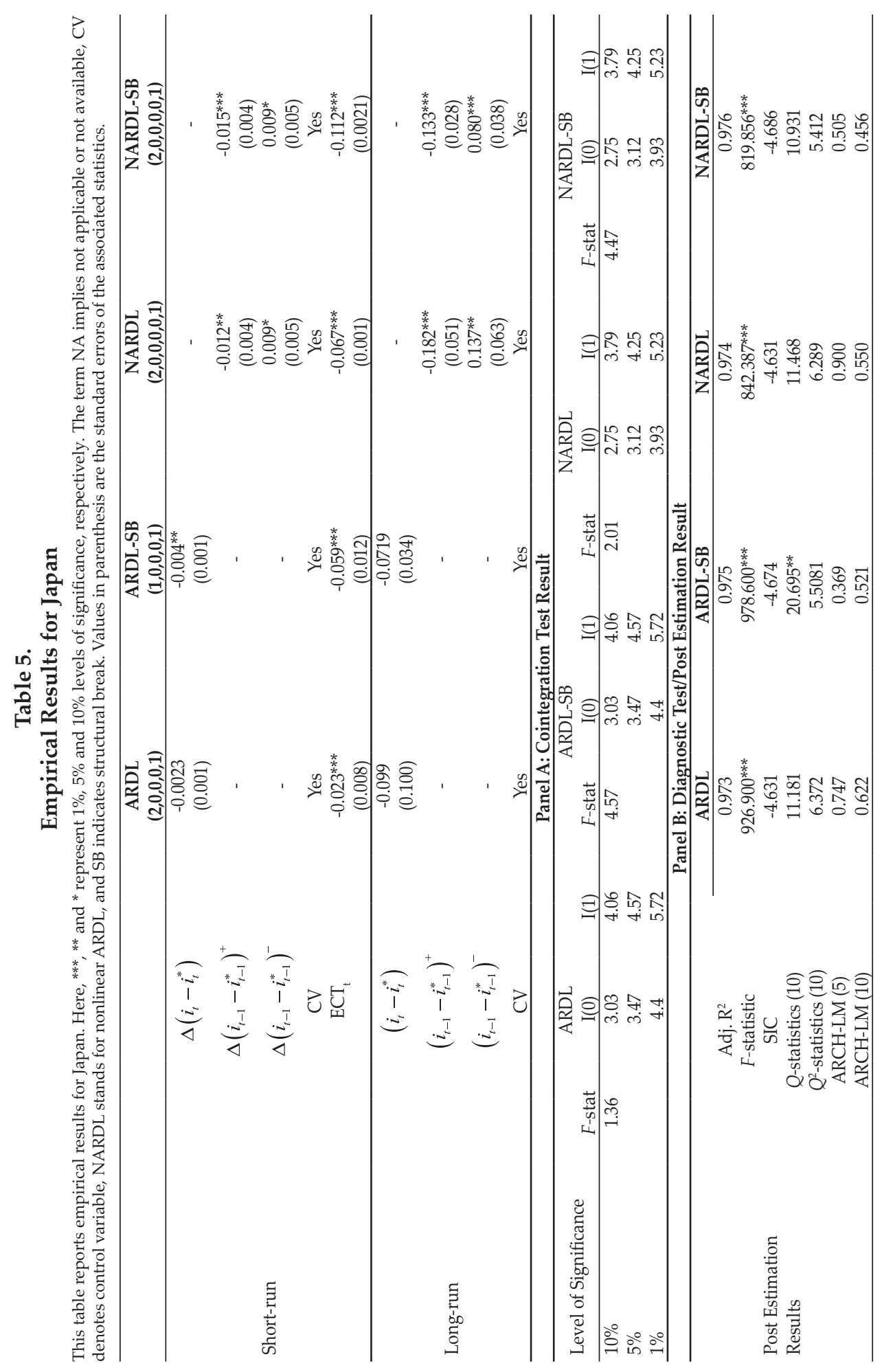




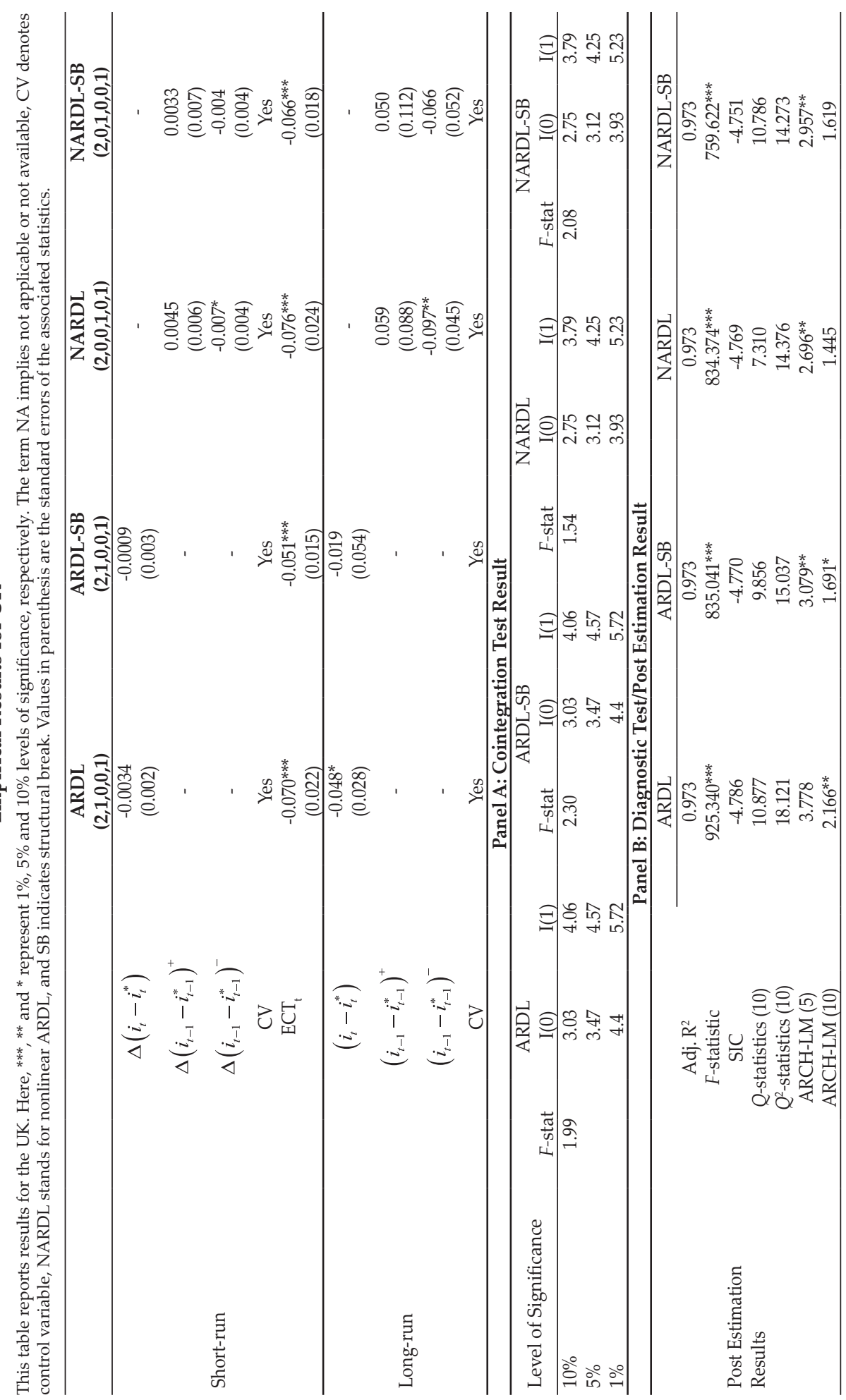




\section{B. Robustness}

We test the sensitivity of our estimates to gain confidence in the results. A number of processes exist for this, including the prominent adoption of different proxies for one or more variables in the model or alternative data frequencies, for example. We embrace the second option, banking on previous clues that the predictability models of financial series such as those assessed here could be sensitive to the choice of data frequency (e.g., Narayan and Liu, 2015; Narayan and Sharma, 2015; Salisu and Adeleke, 2016; Narayan et al., 2018; Salisu, Ndako, and Oloko, 2019). Hence, having employed monthly observations in the main analysis, we thought it revealing to determine the sensitivity of the results using a quarterly data frequency. The effort proved instructive (see Table 7). For brevity, we implement it for the best models for each case identified in the main analysis, that is, the nonlinear ARDL with structural breaks for the euro area unit and the linear ARDL with structural breaks for each of the non-euro countries. As in the main analysis, the positive and negative interest rate differential asymmetries produce positive and negative effects on the exchange rate, respectively. Additionally, the results for Canada support the flexible price hypothesis, whereas those for Japan and the United Kingdom provide weak evidence showing affinity to the sticky price hypothesis, as for the main results. In passing, we reject across the board the null of no cointegration between the variables, supporting the earlier choice of the underlying models when we considered a monthly data frequency.

\section{CONCLUSION}

Using the cases of the euro and non-euro G7 countries, we explore both the conventional and augmented versions of ARDL models to simultaneously capture the need for asymmetry and structural breaks in the exchange rate-interest rate differential nexus. We advanced theoretical, empirical, and technical reasons for considering asymmetry and structural breaks in the relation. Further, we were theoretically motivated by the possibility of testing the validity, or otherwise, of the flexible/sticky price hypotheses in the countries. Consequently, we find that the consideration of structural breaks matters in the nexus and is more prominent than asymmetry. When we compare the results for the euro and non-euro G7 countries, we highlight that the nonlinear ARDL with structural breaks is the best model for the former, while the linear ARDL with structural breaks gives the better estimates in the latter. We inform policymakers of the need to note differences in the empirical results, with the strongest evidence of the sticky price hypothesis found for Japan and lesser evidence for the euro area and the United Kingdom, and strong evidence of the flexible price hypothesis for Canada. In sum, we demonstrate the credibility of our results for an alternative data frequency, as revealed through monthly observations. 


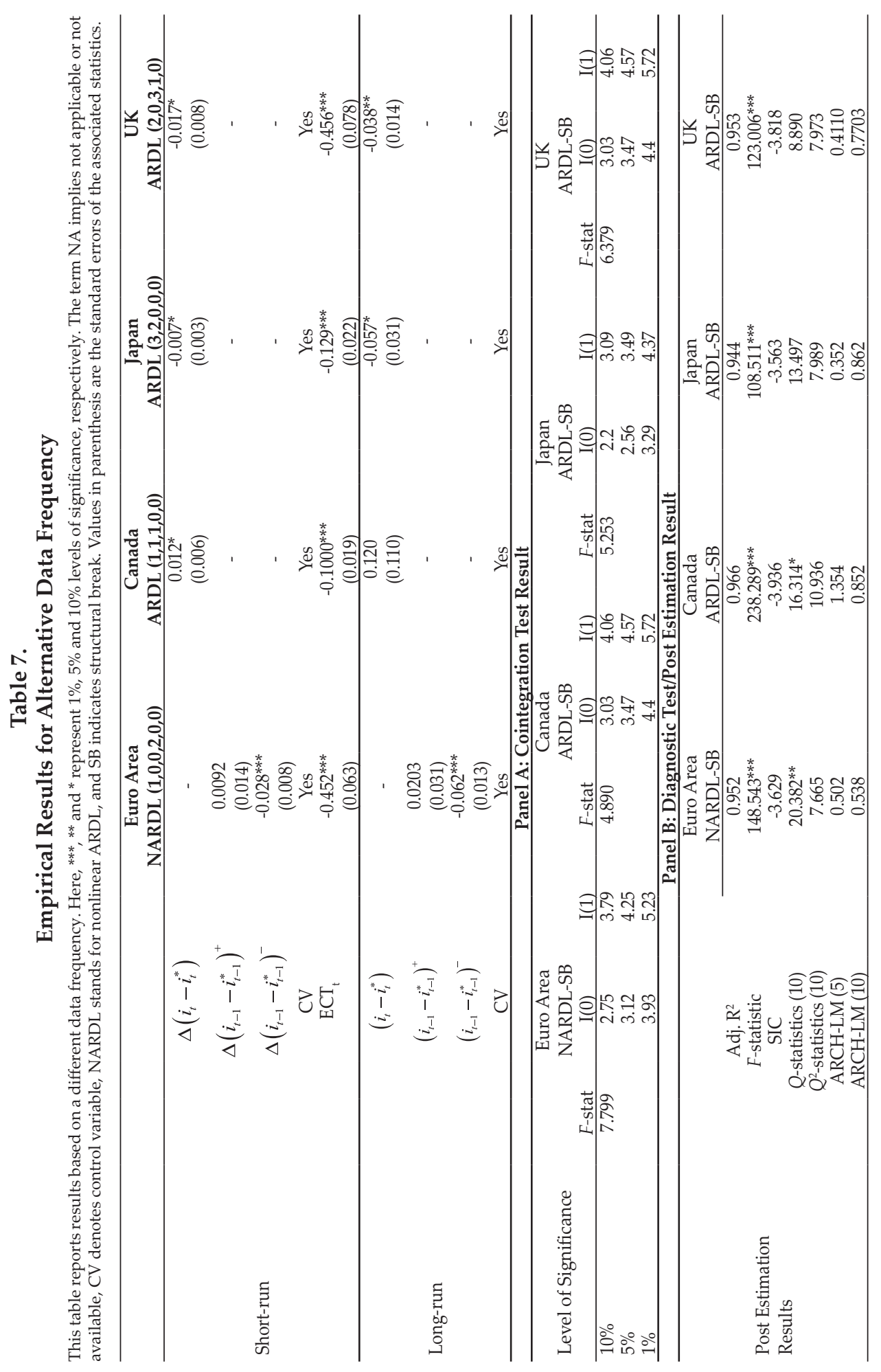




\section{REFERENCES}

Auten, J.H. (1963). Forward Exchange Rates and Interest-Rate Differentials. Journal of Finance, 18, 11-19.

Bahmani-Oskooee, M., and Aftab, M. (2017a). Asymmetric Effects of Exchange Rate Changes on The Malaysia-EU Trade: Evidence from Industry Data. Empirica, 44, 339-365.

Bahmani-Oskooee, M., and Aftab, M. (2017b). On the Asymmetric Effects of Exchange Rate Volatility on Trade flows: New Evidence from US-Malaysia Trade at the Industry Level. Econ. Modell, 63, 86-103.

Bahmani-Oskooee, M., and Kanitpong, T. (2017). Do Exchange Rate Changes Have Symmetric or Asymmetric Effects on the Trade Balances of Asian Countries?. Appl. Econ, 49,4668-4678.

Bahmani-Oskooee, M. and Motavallizadeh-Ardakani, A. (2018). Exchange Rate Changes and Income Distribution in 41 Countries: Asymmetry Analysis. The Quarterly Review of Economics and Finance, 68, 266-282.

Bautista, C.C. (2006). The Exchange Rate-Interest Differential Relationship in Six East Asian Countries. Economics Letters, 92, 137-142.

Bianco, M.D., Camacho M. and Quiros, G.P. (2012). Short-Run Forecasting of the Euro-Dollar Exchange Rates with Economic Fundamentals. Journal of International Money and Finance, 31, 377-396.

Bilson, J. (1978). The Monetary Approach to the Exchange Rate - Some Empirical Evidence. International Monetary Fund Papers, 25, 48-75.

Cheikh, N.B. and Zaied, Y.B. (2019). Revisiting the Pass-Through of Exchange Rate in the Transition Economies: New Evidence from New EU Member States. Journal of International Money and Finance, https://doi.org/10.1016/j. jimonfin.2019.102093

Christodoulakis, G. and Mamatzakis, E. (2013). Behavioural Asymmetries in the G7 Foreign Exchange Market. International Review of Financial Analysis, 29, 261-270.

Civcir, I. (2003). The Monetary Models of the Turkish Lira/U.S. Dollar Exchange Rate: Long-Run Relationships, Short-Run Dynamics, and Forecasting. Eastern European Economics, 41, 43-63.

Ding, L. and Yang, Q. (2017). Asymmetric Impact of Monetary Surprises on Exchange Rate. Applied Economics, 50, 789-803.

Dornbusch, R. (1976). Expectations and Exchange Rate Dynamics. Journal of Political Economy, 84, 1161-1176.

Frankel, J.A. (1979). On the Mark: A Theory Offloating Exchange Rates Based on Real Interest Differentials. American Economic Review, 69, 610-622.

Frankel, J.A. (2014). On The Mark: A Theory of Floating Exchange Rates Based on Real Interest Differentials. The American Economic Review, 69, 610-622.

Frenkel, J. (1976). A Monetary Approach to The Exchange Rate: Doctrinal Aspects and Empirical Evidence. Scandinavian Journal of Economics, 78, 255-76.

Ghartey, E.E. (2018). Asymmetries in Exchange Rate Pass-Through and Monetary Policy Principle: Some Caribbean Empirical Evidence. North American Journal of Economics and Finance, 47, 325-335. 
Hacker, R.S., Karlsson, H.K. and Månsson, K. (2013). An Investigation of The Causal Relations Between Exchange Rates and Interest Rate Differentials Using Wavelets. International Review of Economics and Finance, 29, 321-329.

Hanisch, M. (2019). US Monetary Policy and The Euro Area. Journal of Banking and Finance, 100, 77-96.

Heimonen, K. (2009). The Euro-Dollar Exchange Rate and Equity Flows. Review of Financial Economics, 18, 202-209.

Hooper, P. and Morton, J. (1982). Fluctuations in the Dollar: A Model of Nominal and Real Exchange Rate Determination. Journal of International Money and Finance, 1, 39-56.

Jackman, M., Craigwell, R., and Doyle-Lowe, M. (2013). Nonlinearity in the Reaction of the Foreign Exchange Market to Interest Rate Differentials: Evidence from A Small Open Economy With A Long-Term Peg. Applied Financial Economics, 23, 287-296

Kilian, L. and Taylor, M.P. (2003). Why Is It So Difficult to Beat the Random Walk Forecast of Exchange Rates? Journal of International Economics, 60, 85-107.

Li, X. (2011). How Do Exchange Rates Co-Move? A Study on the Currencies of Five Inflation-Targeting Countries. Journal of Banking \& Finance, 35, 418-429.

Meese, R. and Rogoff, K. (1983). Empirical Exchange Rate Models of the Seventies: Do They Fit Out of Sample? Journal of International Economics, 14, 3-24.

Moosa, I. (2013). Why Is It So Difficult to Outperform the Random Walk in Exchange Rate Forecasting? Applied Economics, 45:23, 3340-3346.

Moosa, I., and Burns, K. (2014). Error Correction Modelling and Dynamic Specifications as A Conduit to Outperforming the Random Walk in Exchange Rate Forecasting. Applied Economics, 46, 3107-3118.

Narayan, P.K., and Liu, R. (2015). A Unit Root Model for Trending Time-Series Energy Variables. Energy Econ. 50, 391-402.

Narayan, P.K. and Popp, S. (2010). A New Unit Root Test with Two Structural Breaks in Level and Slope at Unknown Time. J. Appl. Stat., 37, 1425-1438.

Narayan, P.K. and Sharma, S.S. (2015). Does Data Frequency Matter for the Impact of Forward Premium On Spot Exchange Rate? Int. Rev. Financ. Anal. 39, 45-53.

Ozcelebi, O. (2019). Assessment of Asymmetric Effects on Exchange Market Pressure: Evidence from Emerging Countries. North American Journal of Economics E Finance, 48, 498-513.

Özmen, M.U., and Yilmaz, E. (2017). Co-Movement of Exchange Rates with Interest Rate Differential, Risk Premium and FED Policy in "Fragile Economies". Emerging Markets Review, 33, 173-188.

Rocha, M.D. (2012). Interest Rate Pass-Through in Portugal: Interactions, Asymmetries and Heterogeneities. Journal of Policy Modeling, 34, 64-80.

Salisu, A.A. and Adeleke, A.I. (2016). Further Application of Narayan and Liu (2015) Unit Root Model for Trending Time Series. Econ. Modell, 55, 305-314.

Salisu, A.A. and Ndako, U.B. (2018). Modelling Stock Price -Exchange Rate Nexus in OECD Countries: A New Perspective. Economic Modelling, 74, 105-123.

Salisu, A.A., Adediran,I.A., Oloko, T.F. and Ohemeng, W. (2019). The Heterogeneous Behaviour of the Inflation Hedging Property of Cocoa. North American Journal of Economics and Finance, DOI: https://doi.org/10.1016/j.najef.2019.101093 
Salisu, A.A., Ndako, U.B. and Oloko, T.F. (2019). Assessing the Inflation Hedging of Gold and Palladium in OECD Countries. Resources Policy, 62, 357-377.

Shin, Y., Yu, B., and Greenwood-Nimmo, M. (2014). Modelling Asymmetric Cointegrationand Dynamic Multipliers in An ARDL Framework. Horrace, W.C. 
This page is intentionally left blank 